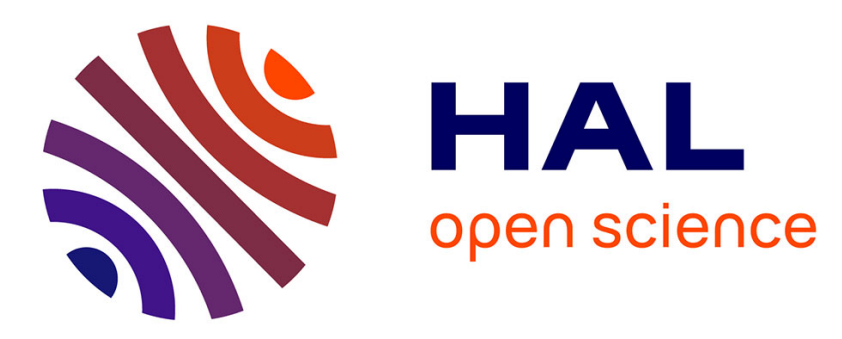

\title{
Relaxation study of a 3d5 ion in Td symmetry: Mn+ + in Zns
}

\author{
A. Deville, C. Blanchard, B. Gaillard, J.P. Gayda
}

\section{To cite this version:}

A. Deville, C. Blanchard, B. Gaillard, J.P. Gayda. Relaxation study of a 3d5 ion in Td symmetry: Mn+ + in Zns. Journal de Physique, 1975, 36 (11), pp.1151-1163. 10.1051/jphys:0197500360110115100 . jpa-00208361

\section{HAL Id: jpa-00208361 https://hal.science/jpa-00208361}

Submitted on 1 Jan 1975

HAL is a multi-disciplinary open access archive for the deposit and dissemination of scientific research documents, whether they are published or not. The documents may come from teaching and research institutions in France or abroad, or from public or private research centers.
L'archive ouverte pluridisciplinaire HAL, est destinée au dépôt et à la diffusion de documents scientifiques de niveau recherche, publiés ou non, émanant des établissements d'enseignement et de recherche français ou étrangers, des laboratoires publics ou privés. 


\title{
RELAXATION STUDY OF A $3 \mathrm{~d}^{5}$ ION IN T $_{\mathrm{d}}$ SYMMETRY : $\mathrm{Mn}^{++}$in $\mathrm{ZnS}$
}

\author{
A. DEVILLE, C. BLANCHARD, B. GAILLARD, J. P. GAYDA \\ Département d'Electronique (*) Université de Provence, Centre de Saint-Jérôme \\ 13397 Marseille Cedex 4, France
}

(Reçu le 18 juillet 1974, révisé le 3 juin 1975, accepté le 12 juin 1975)

\begin{abstract}
Résumé. - On a étudié la relaxation de l'ion $\mathrm{Mn}^{2+}$ dans $\mathrm{ZnS}$ cubique entre 1,3 et $135 \mathrm{~K}$, à 9,3 GHz, par une technique d'impulsion saturante. A basse température, la variation du signal de retour à l'équilibre en fonction de la durée de l'impulsion saturante montre que le système acquiert une température de spin avant de relaxer. Le processus de diffusion qui maintient cette température de spin ne dépend pas de la température; il a une constante de temps $T_{\mathrm{D}}=0,5 \mathrm{~ms}$. Des études complémentaires avec une technique de balayage rapide en champ magnétique confirment que l'ensemble des 30 raies R.P.E. acquiert une température de spin. Quand $T<10 \mathrm{~K}$, la relaxation est assurée par un processus direct et $T_{1} T=1,18 \mathrm{Ks}$. Quand $T_{1}>10 \mathrm{~K}$, on observe un processus $\operatorname{Raman}\left(\frac{1}{T_{1}} \propto T^{7} I_{6}\left(\frac{168}{T}\right)\right)$. Dans le cas du processus direct, un hamiltonien dynamique, établi à partir de mesures sous contrainte uniaxiale, rend bien compte de la relaxation. Une détermination de la contribution Raman à la relaxation a été effectuée avec le modèle des modes normaux de vibration de Van Vleck; elle fournit une valeur de $T_{1}$ qui est d'un ordre de grandeur supérieure à la valeur expérimentale. Dans les deux cas, les phonons transverses sont les plus efficaces.
\end{abstract}

\begin{abstract}
The relaxation behaviour of $\mathrm{Mn}^{2+}$ in cubic $\mathrm{ZnS}$ has been studied between 1.3 and $135 \mathrm{~K}$, at $9.3 \mathrm{GHz}$, with a pulse saturation method. At low temperatures, the variation of the recovery signal with the saturating pulse duration indicates that the system acquires a spin-temperature before relaxing. The diffusion process maintaining the spin-temperature is temperature independent and has a time constant $T_{\mathrm{D}}=0.5 \mathrm{~ms}$. Complementary studies using a fast field sweep technique confirm that the whole system of $30 \mathrm{EPR}$ lines acquires a spin temperature. When $T<10 \mathrm{~K}$, relaxation takes place via a direct process, and $T_{1} T=1.18 \mathrm{Ks}$. When $T_{1}>10 \mathrm{~K}$, we observe a Raman process $\left(\frac{1}{T_{1}} \propto T^{7} I_{6}\left(\frac{168}{T}\right)\right)$. In the case of the direct process, relaxation is well described by a dynamic hamiltonian deduced from uniaxial stress measurements. A determination of the Raman contribution to relaxation made with Van Vleck's normal mode formalism leads to a $T_{1}$ value which is an order of magnitude greater than the experimental value. In both cases tranverse phonons are the most efficient.
\end{abstract}

1. Introduction. - Theoretical studies have shown that several mechanisms may be effective in the relaxation of $3 \mathrm{~d}^{5}$ ions in an $\mathrm{S}$ ground state $\left(\mathrm{Cr}^{+}\right.$, $\left.\mathrm{Mn}^{2+}, \mathrm{Fe}^{3+}\right)$ [1, 2]. Few experimental results are available concerning the relaxation behaviour of $\mathrm{Mn}^{2+}$ in cubic $\mathrm{ZnS}$ [3]. Some care should be taken when studying this system because stacking faults are often present and give rise to complex E.S.R. spectra [4]. The necessary information about the crystal structure and spin hamiltonian is given in section 2 .

(*) E.R.A. No 375, Work supported by C.N.R.S. (A.T.P. 1A 9901).
In section 3, we describe the experimental devices. We give a brief description of the systems which permit easy variation of the saturating pulse duration and fast field sweeping after saturation of a definite transition. These devices were used to elucidate the relaxation mechanisms.

The experimental results for the relaxation of $\mathrm{Mn}^{2+}$ in cubic $\mathrm{ZnS}$ in the temperature range 1.3$135 \mathrm{~K}$ are given in section 4 . The variation of $T_{1}$ versus $T$ is reported. Furthermore, we establish the existence of a temperature-independent diffusion process at low temperatures.

In section 5, we make a determination of the spin- 
lattice relaxation time for both the direct and Raman processes. We study the direct process with a dynamic hamiltonian where the spin-lattice coefficients $G_{i j k l}$ are deduced from static measurements. We examine the Raman process according to Van Vleck's normal mode formalism. We discuss theoretical and experimental results.

2. Crystal structure. Spin hamiltonian. - The lattice is f.c.c. The basis contains one $\mathrm{Zn}$ atom $(0,0,0)$ and one $\mathrm{S}$ atom $(a / 4, a / 4, a / 4$ with $a=5.41 \AA)$. The crystal may be viewed as resulting from the packing of double layers along the $[111]_{\mathrm{W}}$ direction (packing axis). This is noted $\mathrm{A} \alpha \mathrm{B} \beta \mathrm{C} \gamma$, where $\mathrm{A}, \mathrm{B}, \mathrm{C}$ refer to $\mathrm{Zn}$ atoms, $\alpha, \beta, \gamma$ to $\mathbf{S}$ atoms. Stacking faults are often present in cubic $\mathrm{ZnS}$. They give rise to different $\mathrm{Mn}^{2+}$ E.S.R. spectra : if the crystal field is considered to be due to the 1st, 2nd and 3rd nearest neighbours (n.n) only, and if it is remarked that for any sequence of layers the 1 st $\mathrm{n} . \mathrm{n}$ of a $\mathrm{Mn}^{2+}$ ion always form a regular tetraedron, the 2nd $\mathrm{n} . \mathrm{n}$ form a prism (P) or antiprism $(\mathrm{N})$, and there is a single $(\mathrm{S})$ or no $(\mathrm{N}) 3 \mathrm{rd} \mathrm{n} . \mathrm{n}$ on the stacking axis, then only four distinct sites may exist. They are called AN, AS, PN, PS [4]. The symmetry is $T_{d}$ for $A N, C_{3 v}$ for the other sites. Since the substitution of the $\mathrm{B} \beta$ layer by $\mathrm{C} \gamma$ corresponds to a $180^{\circ}$ rotation, which does not belong to $T_{d}$ nor $C_{3 v}$, two homologous centers are obtained for each site AN, AS, PN, PS. The spin hamiltonian is not invariant under this rotation and a splitting of all E.S.R. lines is observed.

Most experiments were done on a synthetic cubic crystal (Eagle Picher Industries, $10^{-4}$ atom $\mathrm{g} \mathrm{Zn}$ per $\mathrm{ZnS}$ mole). Because of the existence of stacking faults, relaxation was studied mainly for $\mathbf{H} / /[111]_{\mathrm{W}}$, where the two cubic systems of lines coalesce (Fig. 1). The axial lines were much weaker than the cubic lines and in the following the presence of the axial sites will be neglected. Measurements were also made on a natural sample of zinc blende (concentration $\simeq 5 \times 10^{-6}$ atom $\mathrm{g} \mathrm{Zn}$ per $\mathrm{ZnS}$ mole) without stacking faults, but cross-relaxation with impurities was then present.

The spin hamiltonian coefficients for the cubic site have been derived by Matarese and Kikuchi [5] and Schneider et al. [6]. The spin hamiltonian is written :

$$
\mathscr{H}=g \beta \mathbf{H S}+A \mathbf{I S}+\frac{a}{6}\left[S x^{4}+S y^{4}+S z^{4}-\frac{707}{16}\right]
$$

where $S=\frac{5}{2}, I=\frac{5}{2}, g$ and $A$ are isotropic,

$$
g=2.0025 \pm 0.0002, A=-68.5 \mathrm{G}, a=+8.42 \mathrm{G},
$$

$x, y, z$ are the cubic axes of the site. Since Zeeman energy $\gg A \gg a$, the eigenstates may be labelled $\left|M_{s}, M_{I}\right\rangle$, the EPR transitions are

$$
\left|M_{S}, M_{I}\right\rangle \leftrightarrow\left|M_{S}-1, M_{I}\right\rangle,
$$

and the EPR spectrum consists of six hyperfine groups of five fine structure lines.

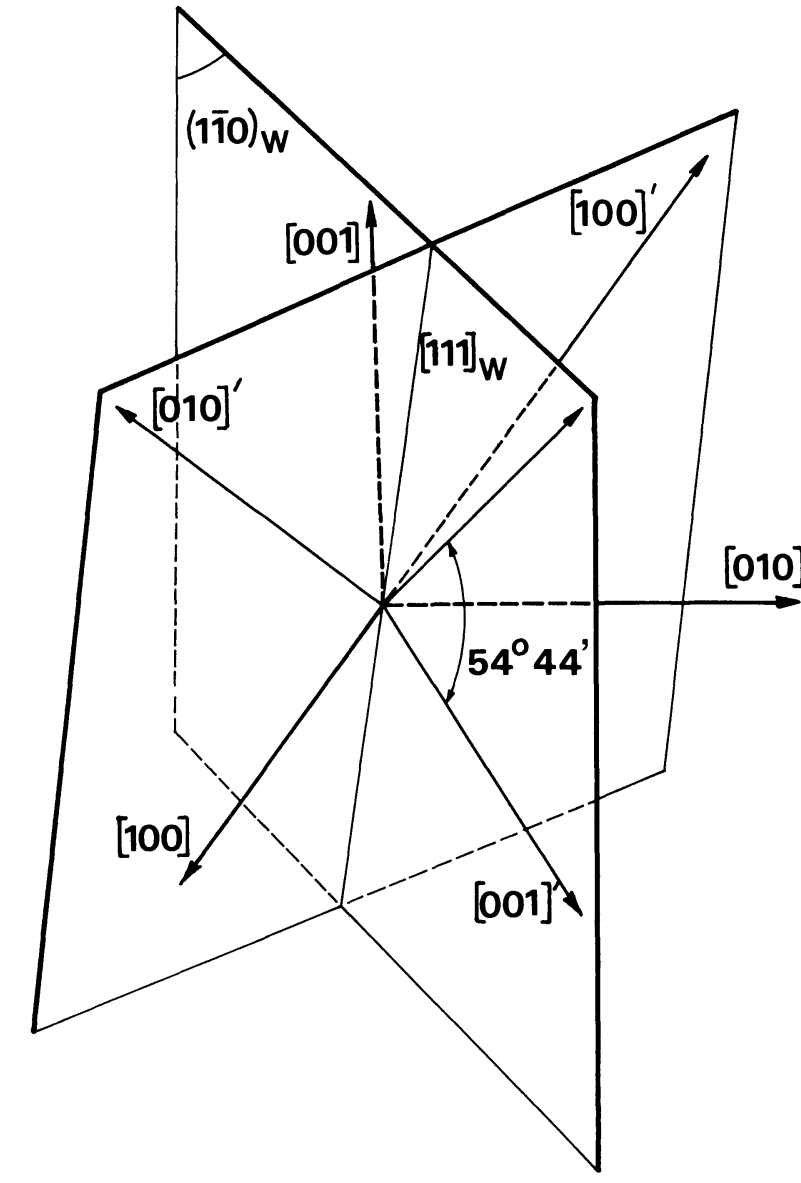

Fig. 1. - Geometry for the two homologous cubic centers in $\mathrm{ZnS}$. The crystallographic axes [100]', [010]' and [001]' of one center are obtained by rotating, around the $[111]_{\mathrm{W}}$ axis, the crystallographic axes of the other centers. The parameter of the spin hamiltonian are identical for the two centers.

3. Experimental conditions. - Experiments were done using an $\mathrm{X}$ band spectrometer previously described [7]. It uses a superheterodyne detection $\left(f_{\mathrm{IF}}=30 \mathrm{Mc} / \mathrm{s}\right)$ and a single klystron (Varian V58, $500 \mathrm{~mW}$ ). Some elements were added to allow low power and pulse measurements. A block diagram of the device is given. in figure 2. Low power measurements $\left(10^{-9} \mathrm{~W}\right.$ range) were made possible by the introduction of a Yig filter and a transmission cavity between single side-band modulator (S.S.M.) and mixer to filter out residual waves from the modulator. The spurious I.F. voltage at the mixer output was then less than the voltage obtained from a $10^{-10} \mathrm{~W}$ r.f. power incident on the signal input. Pulse measurements were made using two fast switching diodes (Microwave Associates MA 83191 X 20A). The two pulses which controlled the saturating and isolating diodes were locked together (Fig. 3). The saturating pulse (duration $\tau$ ) was initiated a time $\tau_{1}$ after the beginning of the isolating pulse. Its trailing edge was used to cut off the isolating pulse after a delay $\tau_{2}$. We could take $\tau_{1}$ and $\tau_{2}=0.2$ or $1 \mu \mathrm{s} ; \tau$ could be varied between $10^{-7}$ and $1 \mathrm{~s}$.' The locking allowed easy studies of the influence of the saturating r.f. pulse 


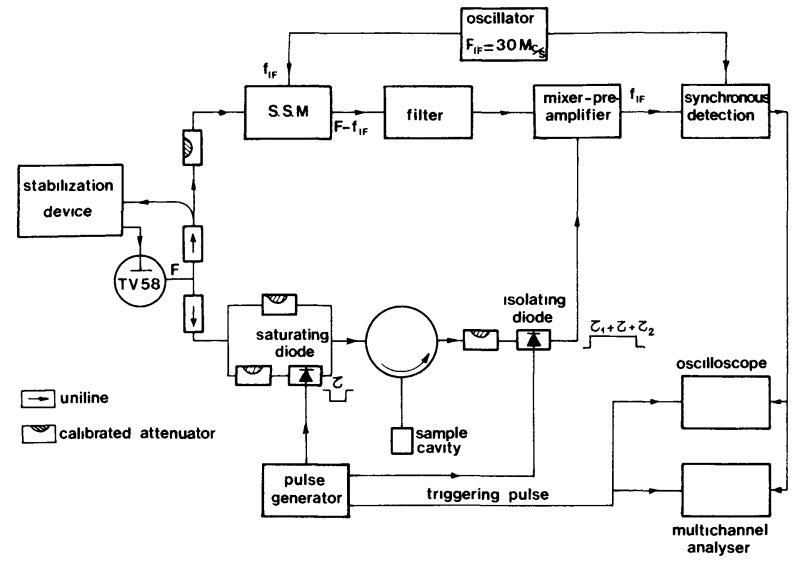

Fig. 2. - Block diagram of the superheterodyne single klystron spectrometer used for spin-lattice relaxation time measurements by a pulse saturation technique.

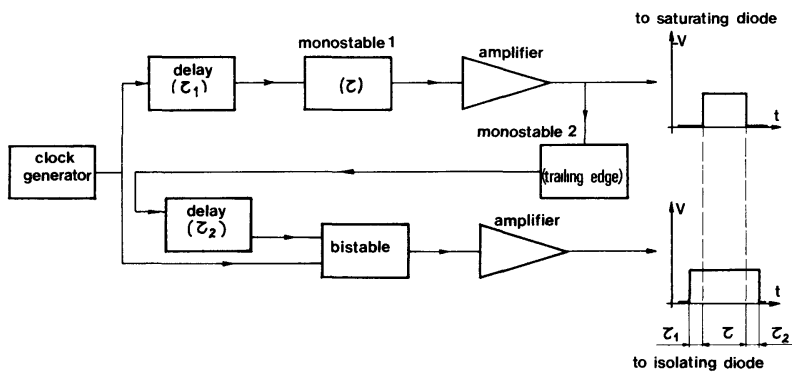

FIG. 3. - The clock generator triggers the bistable and, after a delay $\tau_{1}$, monostable 1 . The trailing edge from monostable 2 triggers back the bistable after a delay $\tau_{2}$.

upon relaxation (only the single parameter $\tau$ had to be varied, the mixer being always protected). Moreover, it was possible to observe the E.S.R. signal recovery $0.2 \mu \mathrm{s}$ after a saturating pulse of arbitrary duration, for instance $1 \mathrm{~s}$. The switching times of the diodes were in the nanosecond range and introduced no limitation. A four-stage filter was used at the output of the I.F. synchronous detector to allow good I.F. suppression with fast rise time $(0.1 \mu \mathrm{s})$.

During pulse experiments, the klystron was frequency-locked to an auxiliary temperature-stabilized cavity (long term stability better than $10 \mathrm{kc} / \mathrm{s}$ ) to avoid saturation of the I.F. chain. For spin-lattice relaxation time measurements, a cylindrical $\mathrm{TE}_{011}$ cavity with $Q_{\mathrm{u}}=2600$ was used. The sample could be rotated around two perpendicular axes and at low temperatures it was immersed in liquid He. Temperatures were measured with an AsGa diode placed near the sample. Studies above $4.2 \mathrm{~K}$ were made by letting the whole cryostat warm up (the passage from 5 to $10 \mathrm{~K}$ took 4 hours).

Studies with field sweeping were done using a rectangular $\mathrm{TE}_{012}$ cavity. Two Helmoltz coils $(\varnothing 20 \mathrm{~mm}, L=60 \mu \mathrm{H}$, with 50 turns of $0.5 \mathrm{~mm}$ copper wire) were placed against the cavity walls. Eddy currents were reduced by cutting a slot in the middle of the large face and bottom $\left(\right.$ at $10^{5} \mathrm{c} / \mathrm{s}$, the modulating field was attenuated by a factor 2). The coils were fed by an electronic device (Fig. 4) which allowed us to create a single sweep of sine wave form at the end of the saturating pulse. We could thus saturate a definite transition without field sweeping; a sweep of large amplitude was moreover possible with neither cavity warming nor helium boiling.

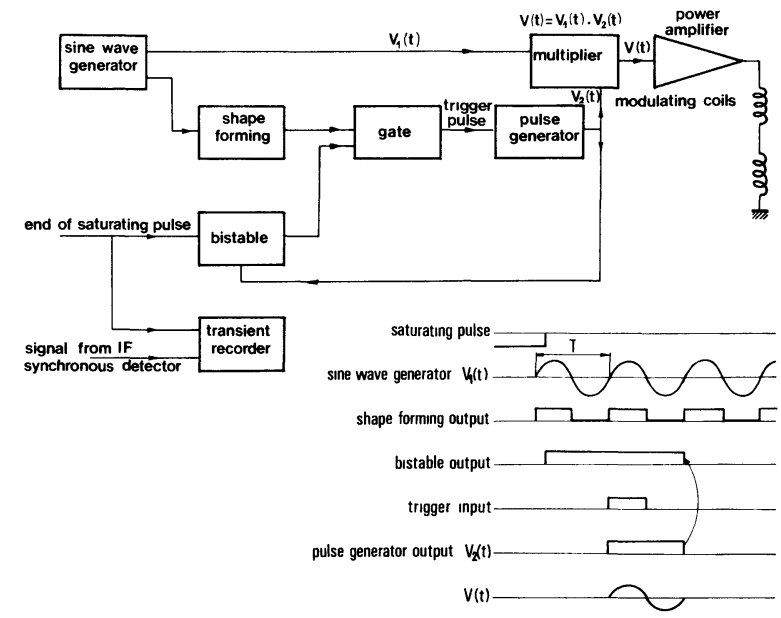

FIG. 4. - Block diagram of the fast field sweep device.

4. Experimental results. - A $0.1 \mathrm{~W}$ r.f. pulse was used to saturate the central line of the $M_{I}=-\frac{1}{2}$ group $\left(\left|\frac{1}{2},-\frac{1}{2}\right\rangle \leftrightarrow\left|-\frac{1}{2},-\frac{1}{2}\right\rangle\right.$ transition) with $\mathbf{H} / /[111]_{\mathbf{w}}$ : At $4.2 \mathrm{~K}$ the analysis of the recovery was made with $P=10^{-7} \mathrm{~W}$. The result was the same with $10^{-8} \mathrm{~W}$ and this point was corroborated by C.W. measurements. The dependence of the recovery signal on the duration $\tau$ of the saturating pulse, is indicated in figure 5. When $\tau=10^{-1} \mathrm{~s}$, a single exponential is recorded (time constant $T_{1}=0.27 \mathrm{~s}$ ). When $\tau=10^{-4} \mathrm{~s}$, the recovery is faster (time constant $T_{\mathrm{D}}=0.5 \mathrm{~ms}$ ). Treatment of the tail end of the signal with a multichannel analyser shows that a second time constant $T_{1}=0.27 \mathrm{~s}$ is still present. For an intermediate $\tau$ value $\left(\tau=10^{-2} \mathrm{~s}\right)$, the two expo-

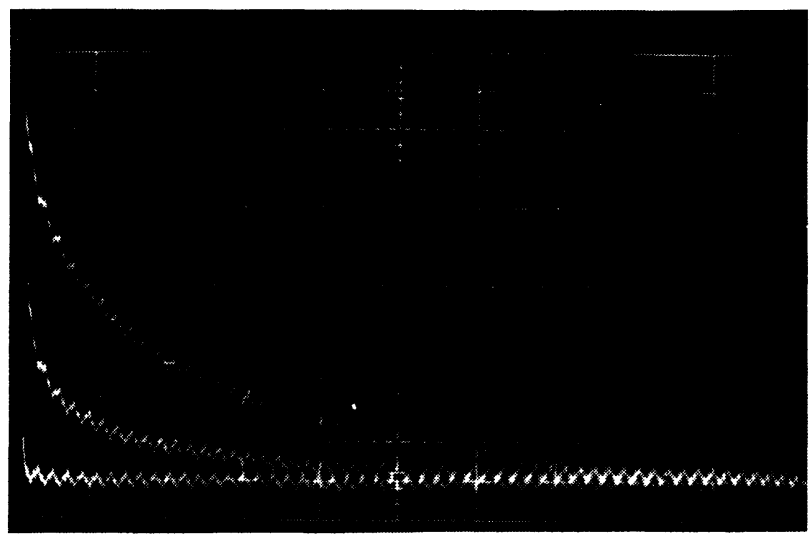

Fig. 5. - Recovery signal observed for different saturating pulse durations $\tau ; T=4.2 \mathrm{~K}, \mathbf{H} / /[111]_{\mathrm{w}}, P_{\mathrm{sat}}=10^{-1} \mathrm{~W}$, $P_{\text {anal }}=10^{-7} \mathrm{~W}$, time base $0.1 \mathrm{~s}$ per large division. Upper curve $\tau=10^{-1} \mathrm{~s}$, middle curve $\tau=10^{-2} \mathrm{~s}$, lower curve $\tau=10^{-4} \mathrm{~s}$. 
nentials are of comparable magnitude. The same measurements were made at $1.34 \mathrm{~K}$ and the same observations were made, with $T_{\mathrm{D}}=0.5 \mathrm{~ms}$ independent of temperature, and $T_{1}=0.88 \mathrm{~s}$. This suggests that $T_{\mathrm{D}}$ is associated with diffusion of energy via temperature independent interactions (dipolar interactions) and $T_{1}$ with spin-lattice relaxation. A field sweep after a saturating pulse gives new information. Figure 6 shows the result obtained when satura-
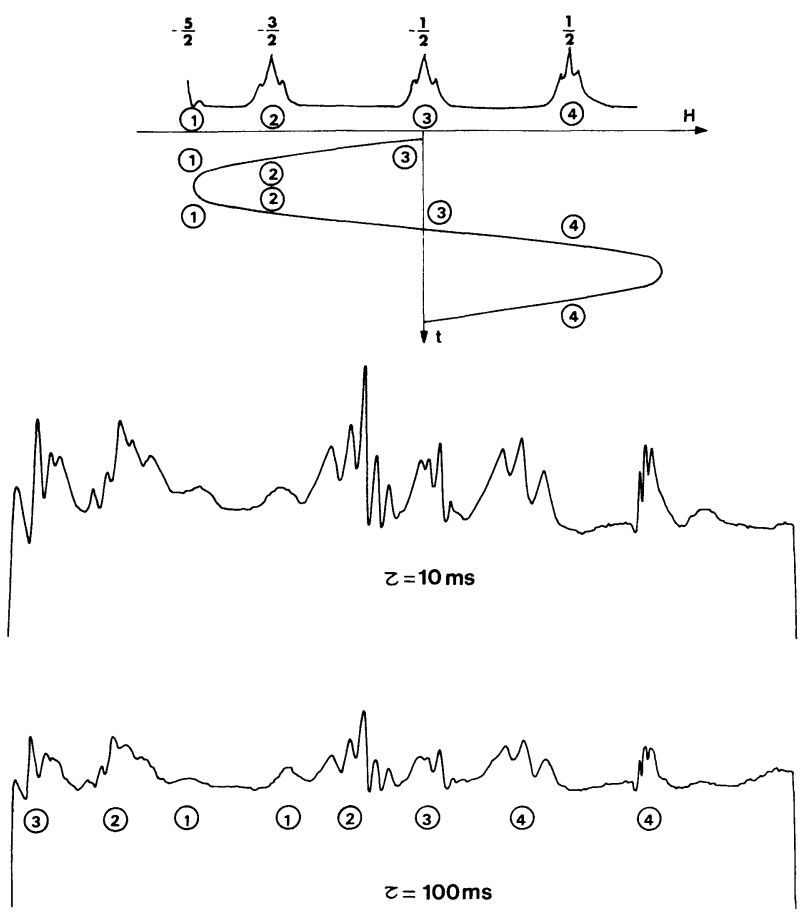

Fig. 6. - Lower curves : Recording of different $M_{I}$ groups of absorption lines for two saturating pulse durations; $\mathbf{H} / /[111]_{\mathbf{W}}$, $T=4.2 \mathrm{~K} . P_{\text {sal }}=10^{-1} \mathrm{~W}, P_{\text {dnal }}=10^{-7} \mathrm{~W}$. The upper curve shows how the lines have been recorded.

ting the $\left|\frac{1}{2},-\frac{1}{2}\right\rangle \leftrightarrow\left|-\frac{1}{2},-\frac{1}{2}\right\rangle$ transition and then observing the $M_{I}=-\frac{1}{2},-\frac{3}{2}, \frac{1}{2}$ groups and part of the $M_{I}=-\frac{5}{2}$ group, with a sine wave of $1 \mathrm{~ms}$ duration and of $180 \mathrm{G}_{\mathrm{pp}}$ magnitude. It was observed that for a pulse duration of $\tau=0.1 \mathrm{~s}$, the intensities of all the observed lines are weaker than when $\tau=10^{-2} \mathrm{~s}$. This indicates that for a long pulse duration the system of the thirty E.P.R. lines is partially saturated, the whole system acquiring a spin temperature during the pulse. Figure 7 was obtained with a shorter sweep $\left(10^{-4} \mathrm{~s}\right)$ around the central line of the $M_{I}=-\frac{1}{2}$ hyperfine group; when $\tau$ increases, one observes first the saturation of the central line then, when $\tau \gg T_{\mathrm{D}}$, the saturation of the other lines. All these experiments show that in the low temperature region (defined by $T_{1}<T_{\mathrm{D}}$ ), relaxation takes place in two steps : establishment of a spin temperature for the whole system of the thirty E.P.R. lines, followed by its relaxation. The recovery of a system with $(2 S+1)$ levels and no diffusion effects would take place through $2 S$ exponentials. It was verified that

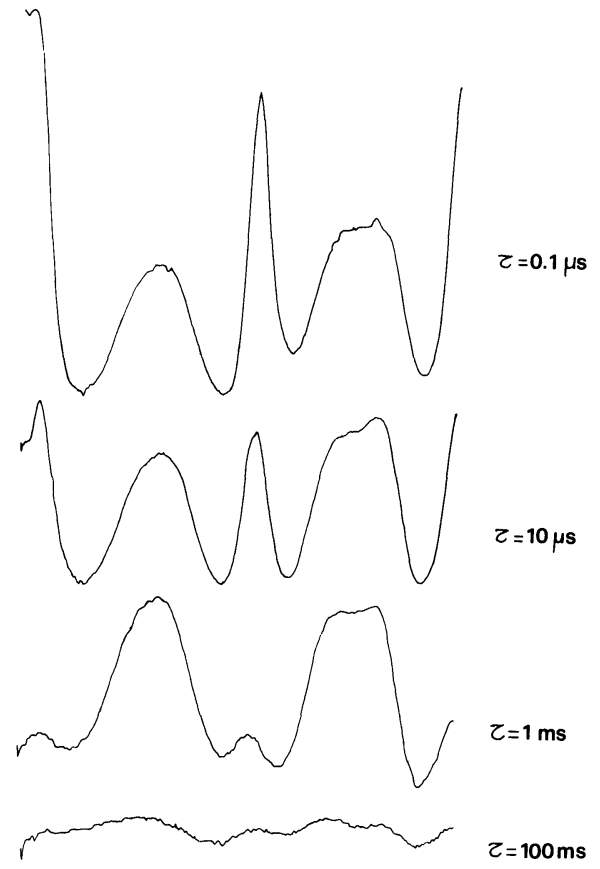

FIG. $7 a$. - Recording of different $M_{S} \rightarrow M_{S}-1$ transitions of the $M_{I}=-\frac{1}{2}$ group for several saturating pulse durations. $\mathbf{H} / /[111]_{\mathrm{w}} . T=4.2 \mathrm{~K}$.
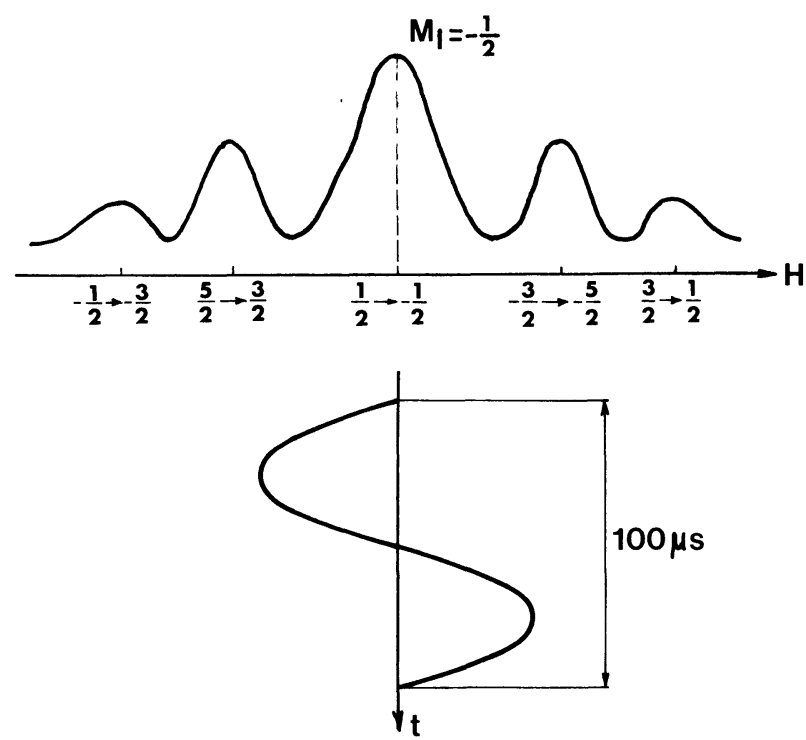

FIG. $7 b .-$ Figure $7 b$ shows how the absorption lines have been recorded.

no variation occurred when $\tau$ was increased from $0.1 \mathrm{~s}$. All the $T_{1}$ measurements were thus made with $\tau=0.1 \mathrm{~s}$. When $T_{1} \geqslant 1 \mathrm{~ms}$ the signal-to-noise ratio was improved with a multichannel analyser.

The experimental results are shown in figures 8 and 9.

When $T_{1}<10 \mathrm{~K}$ :

$$
T_{1} T=1.18 \mathrm{Ks} \quad\left(T_{1}, \mathrm{~s} ; T \mathrm{~K}\right) .
$$




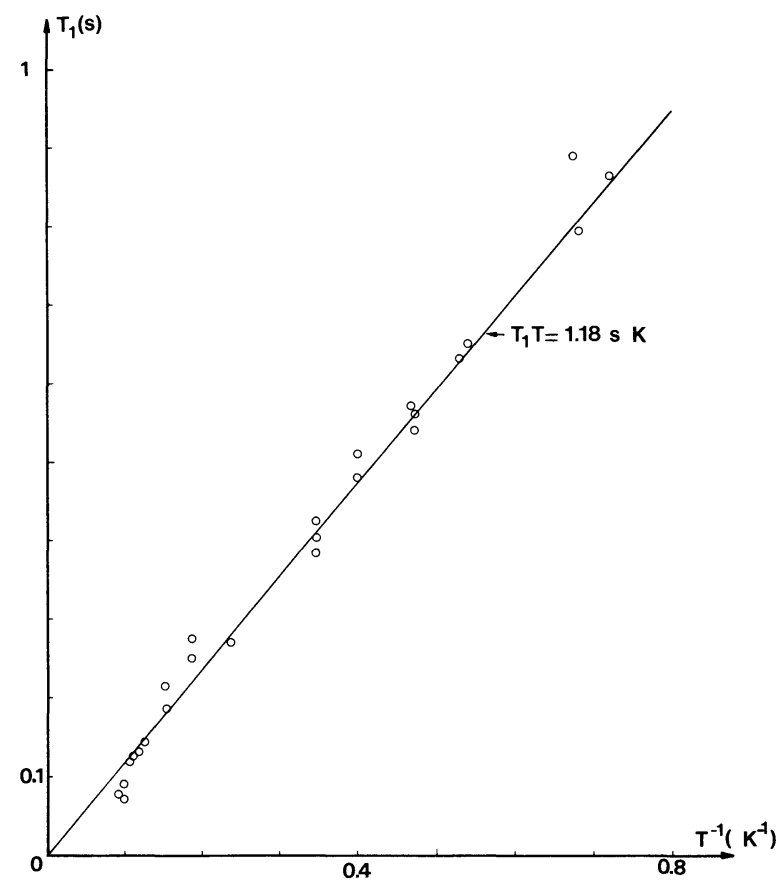

FIG. 8. - Dependence of the spin-lattice relaxation time of $\mathrm{Mn}^{2+}$ in $\mathrm{ZnS}\left(\mathrm{T}_{\mathrm{d}}\right.$ symmetry) in the temperature range $1.3 \mathrm{~K}<T<10 \mathrm{~K}$, H // $[111]_{\mathrm{w}}$, transition $\left|\frac{1}{2},-\frac{1}{2}\right\rangle \rightarrow\left|-\frac{1}{2},-\frac{1}{2}\right\rangle$. These data show a direct process.

When $T_{1}>10 \mathrm{~K}$, the experimental results are in good agreement with the expression :

$\frac{1}{T_{1}}=\frac{T}{1.18}+8.8 \times 10^{-10} T^{7} \times I_{6}\left(\frac{168}{T}\right)$

$\left(T_{1} \mathrm{~s} ; T \mathrm{~K}\right)$

where

$$
I_{6}\left(x_{0}\right)=\int_{0}^{x_{0}} \frac{\mathrm{e}^{x} x^{6} \mathrm{~d} x}{\left(\mathrm{e}^{x}-1\right)^{2}} .
$$

From the numerical expressions of $I_{6}\left(x_{0}\right)$ [8], we can distinguish three regions corresponding to different temperature ranges :

$\begin{array}{cc}x_{0} & I_{6}\left(x_{0}\right) \\ - & - \\ x_{0}>12 & \text { const. } \\ 10>x_{0}>5 & I_{6} \propto x_{0} \\ x_{0} \ll 1 & I_{6} \propto x_{0}^{5}\end{array}$

In the temperature range where the direct process gives no contribution to the spin-lattice relaxation time $(T \geqslant 25 \mathrm{~K})$ we studied for $\mathbf{H} / /[111]_{\mathrm{W}}$ the relaxation time of a line $\left(\left|-\frac{3}{2},-\frac{1}{2}\right\rangle \rightarrow\left|-\frac{5}{2},-\frac{1}{2}\right\rangle\right.$ transition) adjacent to the central one

$$
\left(\left|+\frac{1}{2},-\frac{1}{2}\right\rangle \rightarrow\left|-\frac{1}{2},-\frac{1}{2}\right\rangle\right. \text { transition) . }
$$

We find that the $T_{1}$ values are the same although there is no diffusion effect as it can be checked by our fast field sweep technique.

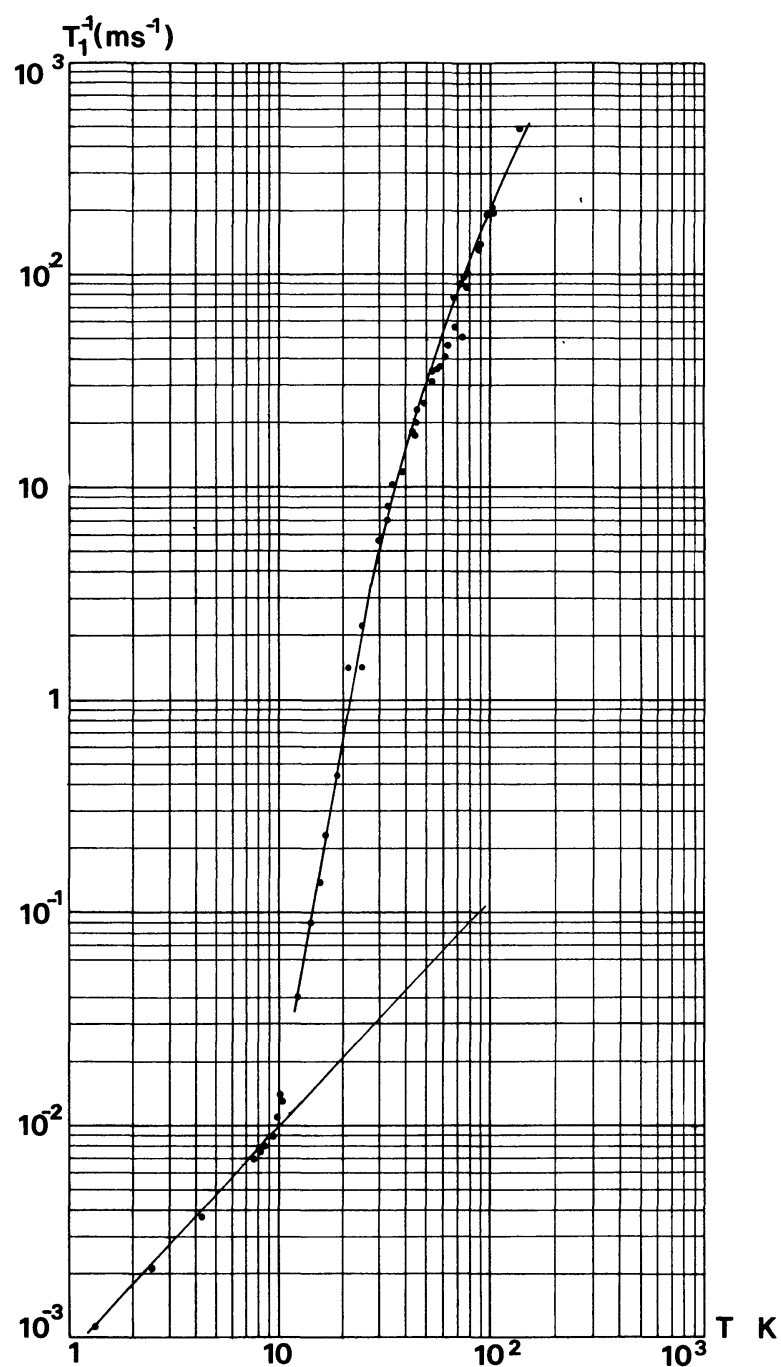

FIG. 9. $-\log$ - $\log$ plot of $1 / T_{1}$ versus $T$ for $\mathrm{Mn}^{2+}$ in $\mathrm{ZnS}\left(\mathrm{T}_{\mathrm{d}}\right.$ symmetry) in the temperature range $1.3 \mathrm{~K}<T<134 \mathrm{~K}$. H / $[111]_{\mathrm{W}}$, transition $\left|\frac{1}{2},-\frac{1}{2}\right\rangle \rightarrow \mid-\frac{1}{2}$. $\left.-\frac{1}{2}\right\rangle$. For $T>20 \mathrm{~K}$, relaxation is caused by a Raman process. The overall data are described by the following expression :

$$
\frac{1}{T_{1}}=\frac{T}{1.18}+8.8 \times 10^{-10} T^{7} I_{6}\left(\frac{168}{T}\right),\left(T_{1} \mathrm{~s}, T \mathrm{~K}\right) .
$$

$T \mathrm{~K}$

$T<14 \mathrm{~K}$

$17 \mathrm{~K}<T<34 \mathrm{~K}$

$T \gg 168 \mathrm{~K}$

$$
1 / T_{1} \text { dependence }
$$$$
1 / T_{1}=A T+\overline{B T^{7}}
$$$$
1 / T_{1}=A T+C T^{6} ; \text { for } T \geqslant 25 \mathrm{~K}
$$$$
1 / T_{1}=D T^{2} \quad \text { the direct pro- }
$$
cess is negligible
Moreover we studied the central line for $\mathbf{H}$ parallel to the principal axis of one of the two cubic systems (H // [001], Fig. 1). Within a factor 2 we found the same temperature dependence as the central line (Fig. 10). This allows us to make a theoretical determination of $T_{1}$ for the Raman process with $\mathbf{H} / /$ [001], where the calculation is easier (cf. § 5).

5. Interpretation of the results. - We have made a theoretical determination of the spin-lattice relaxation 


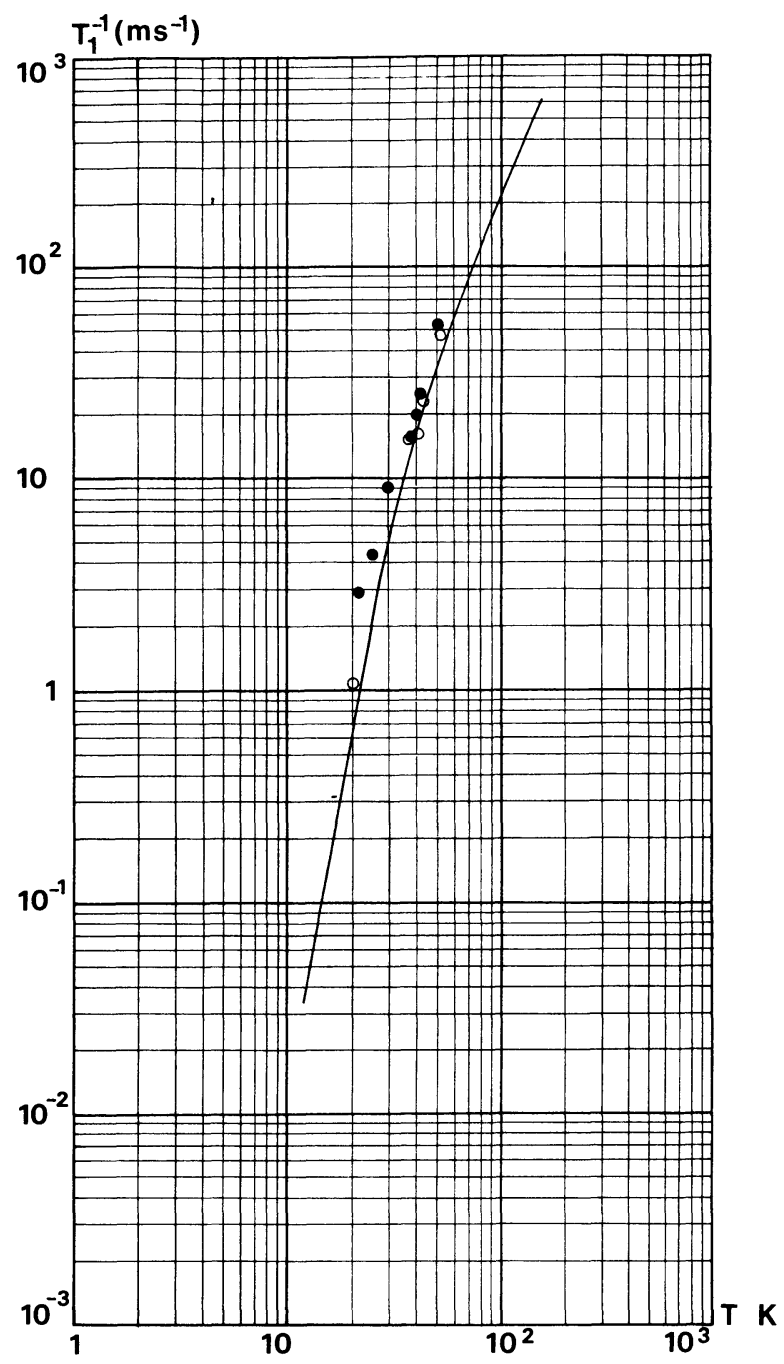

Fig. 10. $-\log -\log$ plot of $1 / T_{1}$ versus $T$ for $\mathrm{Mn}^{2+}$ in $\mathrm{ZnS}\left(\mathrm{T}_{\mathrm{d}}\right.$ symmetry) in the temperature range $20 \mathrm{~K}<T<50 \mathrm{~K}$.

- Transition $\left|-\frac{3}{2},-\frac{1}{2}\right\rangle \rightarrow\left|-\frac{5}{2},-\frac{1}{2}\right\rangle$ for $\mathbf{H} / /[111]_{\mathrm{w}}$. $\bigcirc$ Transition $\left|\frac{1}{2},-\frac{1}{2}\right\rangle \rightarrow\left|-\frac{1}{2},-\frac{1}{2}\right\rangle$ for $\mathbf{H} / /[001]$.

time when the system possesses a spin temperature for both direct and Raman processes.

We describe the system by a dynamic spin hamiltonian and interpret the results in terms of the direct process.

We replace the dynamic spin-lattice coupling coefficients by the values obtained from stress measurements [9]. This approximation is justified because only phonons of low frequency contribute to the relaxation process. In terms of the Raman process. It is assumed that one phonon is absorbed and one is emitted. We keep the linear terms of the dynamic part of the cristalline potential, for the contribution of this term is generally more effective than that of the quadratic terms [10].

We first derive the spin lattice relaxation time when there is a spin temperature.

For our system, in the high-temperature range, the number $N\left(M_{S}, M_{I}\right)$ of centers in the state $\left|M_{S}, M_{I}\right\rangle$ is given by :

$$
N\left(M_{S}, M_{I}\right)=\frac{N}{(2 S+1)(2 I+1)}\left[1-M_{S} \Delta_{S}\right]
$$

where $N$ is the total number of spins,

$$
\Delta_{\mathrm{s}}=\frac{\hbar \omega_{0}}{k T_{\mathrm{s}}}, \quad \omega_{0}=g \beta H,
$$

$T_{\mathrm{S}}$ is the spin temperature.

The energy given up to the lattice per unit time, $\dot{E}_{\mathrm{L}}$, is :

$$
\begin{aligned}
\dot{E}_{\mathrm{L}}=\hbar \omega_{0} \frac{N}{2 S+1}\left(\Delta-\Delta_{\mathrm{S}}\right) & \sum_{K=1}^{2 S+1} \sum_{M_{S}=S}^{-S+K} \times \\
\times & K^{2} W_{M_{S} \rightarrow M_{S}-K}
\end{aligned}
$$

where

$$
\Delta=\frac{\hbar \omega_{0}}{k T},
$$

$T$ is the lattice temperature, $W_{M_{S} \rightarrow M_{S}-K}$ is the relaxation transition probability from state $\left|M_{S}, M_{I}\right\rangle$ to state $\left|M_{S}-K, M_{I}\right\rangle$. The variation per unit time of the spin system energy, $\dot{U}$, is

$$
\dot{U}=\frac{-N}{2 S+1} \hbar \omega_{0} \sum_{M_{S}=S}^{-S}\left(M_{S}\right)^{2} \dot{\Delta}_{\mathrm{S}}
$$

Energy conservation leads to :

$$
\begin{aligned}
& \dot{\Delta}_{\mathrm{S}}=\frac{\Delta-\Delta_{\mathrm{S}}}{T_{1}} \\
& \text { with } \\
& \begin{aligned}
\frac{1}{T_{1}}=\frac{3}{S(S+1)(2 S+1)} \sum_{K} \sum_{M_{S}=S}^{-S+K} \times \\
\times K^{2} W_{M_{S} \rightarrow M_{S}-K} .
\end{aligned}
\end{aligned}
$$

5.1 THE DIRECT PROCESS. - The spin lattice relaxation process is described by the dynamic hamiltonian $H_{\text {SL }}:$

$$
\mathscr{H}_{\mathrm{SL}}=\sum_{i j k l} G_{i j, k l} S_{i} S_{j} \varepsilon_{k l}
$$

$\varepsilon_{k l}$ and $G_{i j, k l}$ are respectively the strain and spinlattice tensor components.

When a stress is applied to a crystal containing paramagnetic ions, its effects on the E.S.R. spectrum can be described by the following spin-hamiltonian :

$$
\mathcal{H}_{\mathrm{stress}}=\sum_{i j k l} C_{i j, k l} S_{i} S_{j} \sigma_{k l}
$$

$\sigma_{k l}$ and $C_{i j, k l}$ are the components of two stress tensors. $G_{i j, k l}$ and $C_{i j, k l}$ have the same symmetry properties 
as the photoelastic tensors and they are related to each other by the stiffness tensor $c_{m n k l}$ :

$$
G_{i j, k l}=\sum_{m n} C_{i j, m n} c_{m n k l}
$$

In the case of $T_{\mathrm{d}}$ symmetry (and using Voigt notation [11]) there are only three independent coefficients,
$G_{11}, G_{12}$ and $G_{44}$. The tracelessness of the spinhamiltonian adds a further condition :

$$
G_{11}+2 G_{12}=0 .
$$

The correspondence between the $G$ 's and $C$ 's is :

$$
\begin{aligned}
G_{11} & =C_{11}\left(c_{11}-c_{12}\right) \\
G_{44} & =C_{44} c_{44} .
\end{aligned}
$$

The detailed expression of $\mathscr{H}_{\mathrm{SL}}$ is [19] :

$$
\begin{aligned}
\mathscr{H}_{\mathrm{SL}}=\frac{G_{11}}{2}\left\{\left[3 S_{x}^{2}-S(S\right.\right. & \left.+1)] \varepsilon_{x x}+\left[3 S_{y}^{2}-S(S+1)\right] \varepsilon_{y y}+\left[3 S_{z}^{2}-S(S+1)\right] \varepsilon_{z z}\right\}+ \\
& +2 G_{44}\left\{\left(S_{y} S_{z}+S_{z} S_{y}\right) \varepsilon_{y z}+\left(S_{z} S_{x}+S_{x} S_{z}\right) \varepsilon_{z x}+\left(S_{x} S_{y}+S_{y} S_{x}\right) \varepsilon_{x y}\right\}
\end{aligned}
$$

where

$$
\varepsilon_{i j}=\frac{1}{2}\left[\frac{\partial u_{i}}{\partial x_{j}}+\frac{\partial u_{j}}{\partial x_{i}}\right]
$$

The $\left(u_{i}\right)$ are the displacement components of the point with coordinates $\left(x_{i}\right)$. This displacement is analysed in terms of phonon operators :

$$
\mathbf{u}(\mathbf{r})=\sum_{\mathbf{k}, s}\left(\frac{\hbar}{2 M \omega_{k s}}\right)^{1 / 2} \mathbf{e}(\mathbf{k}, s)\left[a_{k s} e^{i \mathbf{k r}}+a_{k s}^{+} \mathrm{e}^{-i \mathbf{k r}}\right]
$$

with

$$
a_{k s}^{+}\left|n_{k s}\right\rangle=\left(n_{k s}+1\right)^{1 / 2}\left|n_{k s}+1\right\rangle
$$

$\mathbf{e}(\mathbf{k}, s)$ is the unit vector in the direction of polarization of the mode $(\mathbf{k}, s), M$ is the total mass of the crystal.

The transition probability $W_{M_{S} \rightarrow M_{S}-K}$ from the state $\left|M_{S}, M_{I}\right\rangle$ to $\left|M_{S}-K, M_{I}\right\rangle$ is given by :

$$
W_{M_{S} \rightarrow M_{S}-K}=\frac{V}{4 \pi^{2} \hbar^{2}}\left[\int_{\mathbf{k}} \sum_{L, T_{1}, T_{2}}\left|\left\langle M_{S}-K, n_{k s}+1\left|\mathcal{H}_{\mathrm{SL}}\right| M_{S}, n_{k s}\right\rangle\right|^{2} \frac{\omega_{k s}^{2}}{v_{s}^{3}} \mathrm{~d} \Omega\right]_{\omega_{k s}=K \omega_{0}}
$$

where $V$ is the crystal volume,

$$
\omega_{k s}=v_{s} k
$$

$L, T_{1}, T_{2}$ are the three polarizations (longitudinal, transverse), $\mathrm{d} \Omega$ is related to the possible $\mathbf{k}$ directions. The calculation of $W_{M_{S} \rightarrow M_{S}-K}$ requires the knowledge of the following quantities :

$$
\left\langle\varepsilon_{i j} \varepsilon_{k l}\right\rangle_{s}=\frac{1}{4 \pi} \int\left\langle n_{k s}+1\left|\varepsilon_{i j}\right| n_{k s}\right\rangle\left\langle n_{k s}\left|\varepsilon_{k l}\right| n_{k s}+1\right\rangle \mathrm{d} \Omega=k_{s}^{2}\left(\frac{\hbar}{2 M \omega_{k s}}\right)\left(n_{k s}+1\right)\left\langle f_{i j} f_{k l}\right\rangle_{s} .
$$

The non-zero terms are :

$$
\begin{aligned}
\left\langle f_{i i}^{2}\right\rangle_{L} & =\frac{1}{5} & \left\langle f_{i i}^{2}\right\rangle_{T_{1}}+\left\langle f_{i i}^{2}\right\rangle_{T_{2}} & =\frac{2}{15} \\
\left\langle f_{i j}^{2}\right\rangle_{L} & =\frac{1}{15} & \left\langle f_{i j}^{2}\right\rangle_{T_{1}}+\left\langle f_{i j}^{2}\right\rangle_{T_{2}} & =\frac{1}{10} . \\
\left\langle f_{i i} f_{j j}\right\rangle_{L} & =\frac{1}{15} & \left\langle f_{i i} f_{j j}\right\rangle_{T_{1}}+\left\langle f_{i i} f_{j j}\right\rangle_{T_{2}} & =-\frac{1}{15} .
\end{aligned}
$$


The non-zero probabilities $\left({ }^{1}\right)$ are :

$$
\begin{gathered}
W_{M_{S} \rightarrow M_{S}-1}=\frac{1}{2 \pi \rho} \frac{(g \beta H)^{2}}{\hbar^{4}} k T\left(\frac{1}{v_{L}^{5}}+\frac{3}{2} \frac{1}{v_{T}^{5}}\right) \cdot\left(M_{S}-\frac{1}{2}\right)^{2}\left[S(S+1)-M_{S}\left(M_{S}-1\right)\right] \times \\
\times\left[\frac{3}{5} G_{11}^{2} p+\frac{8}{15} G_{44}^{2}(1-2 p)\right](19 a) \\
W_{M_{S} \rightarrow M_{S}-2}=\frac{1}{2 \pi \rho} \frac{(2 g \beta H)^{2}}{\hbar^{4}} k T\left(\frac{1}{v_{L}^{5}}+\frac{3}{2} \frac{1}{v_{T}^{5}}\right)\left[S(S+1)-M_{S}\left(M_{S}-1\right)\right]\left[S(S+1)-\left(M_{S}-1\right)\left(M_{S}-2\right)\right] \times \\
\times\left[\frac{3}{80} G_{11}^{2}(1-p)+\frac{1}{15} G_{44}^{2}(1+p)\right] \\
v_{T_{1}}=v_{T_{2}}=v_{T}, \quad p=l^{2} m^{2}+m^{2} n^{2}+n^{2} l^{2}
\end{gathered}
$$

where $l, m, n$ are the direction cosines of the applied field $\mathbf{H}$ with the cristalline axes, $\rho$ is the crystal density.

Putting (19) and (20) into (6) leads to the following expression of the spin-lattice relaxation time $T_{1}$ :

$$
\frac{1}{T_{1}}=\frac{3(2 S-1)(2 S+3)}{25 \pi \rho \hbar^{4}}(g \beta H)^{2} k T\left(\frac{1}{v_{L}^{5}}+\frac{3}{2} \frac{1}{v_{T}^{5}}\right)\left[G_{11}^{2}+2 G_{44}^{2}+\left(\frac{4}{3} G_{44}^{2}-\frac{3}{4} G_{11}^{2}\right) p\right]
$$

our experiments have been done for $\mathbf{H} / /[111]_{\mathrm{W}}$. The experimental function gives us a temperature dependence

$$
T_{1} T=1.18 \mathrm{Ks} \text {. }
$$

Taking $p=\frac{1}{3}, \rho=4.1 \mathrm{~g} / \mathrm{cm}^{3}, H=3300 \mathrm{G}, \quad v_{L}=5.8 \times 10^{5} \mathrm{~cm} / \mathrm{s}, \quad v_{T}=2.5 \times 10^{5} \mathrm{~cm} / \mathrm{s}, \quad G_{11}=-3.6 \times 10^{-18} \mathrm{erg}$, $G_{44}=3.6 \times 10^{-17} \mathrm{erg}$ (ref. [9]), we have

$$
T_{1} T=1.61 \mathrm{Ks}
$$

This value agrees with the experimental results.

We see that the $G_{44}^{2}$ value is much greater than $G_{11}^{2}$ so the angular variation is proportional to

$$
G_{44}^{2}\left(1+\frac{2}{3} p\right) \text {. }
$$

If we compare our results with those of Wagner et al. [3] obtained by an adiabatic fast passage method for $\mathbf{H} / /$ [001], we find that

$$
\frac{\left(\frac{1}{T_{1} T}\right)_{\mathbf{H} \|[001]}}{\left(\frac{1}{T_{1} T}\right)_{\mathbf{H} \|[111] \mathbf{W}}}=0.87 .
$$

The theoretical value gives 0.82 .

These results show that a spin temperature was established in the spin system studied by Wagner et al. Moreover they indicate that our model using static spin-lattice coefficients in the determination of the spin-lattice relaxation time is realistic in the case of the direct process.

It is not possible to use the same procedure as above for the Raman process, since no departure from linearity was observed in uniaxial stress measurements [9].

We have also studied a natural crystal of zinc blende. At $4.2 \mathrm{~K}$ we found two time constants

( $\left.{ }^{1}\right)$ We must point out that there are mistakes in the $W$ 's expressions for $W$ given by Kondo. The final result giving $1 / T_{1}$ is correct.
$(5 \pm 2 \mathrm{~ms}$ and $20 \pm 5 \mathrm{~ms})$. These constants were independent of the orientation of the applied field $\mathbf{H}$ with respect to the cristalline axes. These features could be explained by supposing that there is crossrelaxation with fast relaxing impurities.

5.2 ThE RAMAN PROCESS. - We make a direct determination of the spin-lattice relaxation time for $\mathbf{H} / /[001]$, and under the assumption of a spin temperature. Before outlining the explicit calculation of the transition probability $W_{M_{S} \rightarrow M_{S}-K}$ from spin state $\left|M_{S}\right\rangle$ to spin state $\left|M_{S}-K\right\rangle$ with one phonon absorbed and one phonon emitted, we discuss the properties of the first excited states of $\mathrm{Mn}^{2+}$ in cubic $\mathrm{ZnS}$; and we then give the expression for the dynamic part $V_{\mathrm{OL}}$ of the cristalline field, and the perturbation scheme used.

The allowed terms for a $3 \mathrm{~d}^{5}$ configuration are ${ }^{6} \mathrm{~S},{ }^{4} \mathrm{P},{ }^{4} \mathrm{D},{ }^{4} \mathrm{~F},{ }^{4} \mathrm{G}$ and doublets. The expressions for the quartet eigenstates are given by Slater J. C. A cristalline field of $T_{d}$ symmetry may split these terms according to the irreductible representations of $T_{d}$ :

$$
\begin{aligned}
{ }^{6} \mathrm{~S} & \rightarrow{ }^{6} \mathrm{~A}_{1} \\
{ }^{4} \mathrm{P} & \rightarrow{ }^{4} \mathrm{~T}_{1} \\
{ }^{4} \mathrm{D} & \rightarrow{ }^{4} \mathrm{E} \oplus{ }^{4} \mathrm{~T}_{2} \\
{ }^{4} \mathrm{~F} & \rightarrow{ }^{4} \mathrm{~A}_{2} \oplus{ }^{4} \mathrm{~T}_{1} \oplus{ }^{4} \mathrm{~T}_{2} \\
{ }^{4} \mathrm{G} & \rightarrow{ }^{4} \mathrm{~A}_{1} \oplus{ }^{4} \mathrm{E} \oplus{ }^{4} \mathrm{~T}_{1} \oplus{ }^{4} \mathrm{~T}_{2} .
\end{aligned}
$$

The magnitude of the cubic cristalline field $V_{\mathrm{c}}$ and the relative energies of levels ${ }^{4} \mathrm{P},{ }^{4} \mathrm{D},{ }^{4} \mathrm{~F},{ }^{4} \mathrm{G}$ 
are comparable, thus one must diagonalize the ${ }^{4} \mathrm{E}$, three eigenstates of $V_{\mathrm{c}}$ which transform as ${ }^{4} \mathrm{~T}_{1}$ are ${ }^{4} \mathrm{~T}_{1}$ and ${ }^{4} \mathrm{~T}_{2}$ matrices in the presence of $V_{\mathrm{c}}$. The written :

where

$$
\left|{ }^{4} \mathrm{~T}_{1}^{i}, M_{\Gamma}\right\rangle=\alpha_{i}\left|\mathrm{P}^{4} \mathrm{~T}_{1}, M_{\Gamma}\right\rangle+\beta_{i}\left|\mathrm{~F}^{4} \mathrm{~T}_{1}, M_{\Gamma}\right\rangle+\gamma_{i}\left|\mathrm{G}^{4} \mathrm{~T}_{1}, M_{\Gamma}\right\rangle
$$

$$
M_{\Gamma}=1,0,-1 \quad i=1,2,3 .
$$

The expressions of states such as $\left|\mathrm{P}^{4} \mathrm{~T}_{1}, M\right\rangle$ are given by Griffith (ref. [14], A 19). In the same way :

$$
\left|{ }^{4} \mathrm{~T}_{2}^{i}, M_{\Gamma}\right\rangle=\alpha_{i}^{\prime}\left|\mathrm{D}^{4} \mathrm{~T}_{2}, M_{\Gamma}\right\rangle+\beta_{i}^{\prime}\left|\mathrm{F}^{4} \mathrm{~T}_{2}, M_{\Gamma}\right\rangle+\gamma_{i}^{\prime}\left|\mathrm{G}^{4} \mathrm{~T}_{2}, M_{\Gamma}\right\rangle,
$$

$V_{\mathrm{c}}$ is diagonal inside the ${ }^{4} \mathrm{E}$ representation.

The values for $\alpha_{i}, \beta_{i}, \gamma_{i}, \alpha_{i}^{\prime}, \beta_{i}^{\prime}, \gamma_{i}^{\prime}$ and for the energies $E\left({ }^{4} \mathrm{~T}_{1}^{i}\right), E\left({ }^{4} \mathrm{~T}_{2}^{i}\right), E\left(\mathrm{D}^{4} \mathrm{E}\right), E\left(\mathrm{G}{ }^{4} \mathrm{E}\right), E\left(\mathrm{~F}^{4} \mathrm{~A}_{2}\right)$ are given in appendix 1 .

We must finally note that the spin-orbit interaction couples the ground-state $\left|{ }^{6} \mathrm{~A}_{1} M_{S}\right\rangle$ to the excited states $\left|{ }^{4} \mathrm{~T}_{1}, 1\right\rangle,\left|{ }^{4} \mathrm{~T}_{1}, 0\right\rangle,\left|{ }^{4} \mathrm{~T}_{1},-1\right\rangle$.

The admixed wave-functions are :

$$
\begin{aligned}
\left|{ }^{6} \mathrm{~A}_{1}^{\prime}, M_{S}\right\rangle=\left|{ }^{6} \mathrm{~A}_{1}, M_{S}\right\rangle-\sum_{i=1}^{3} \frac{\alpha_{i}}{\Delta_{i}} \zeta\left[a\left(M_{S}\right)\left|{ }^{4} \mathrm{~T}_{11}^{(i)}, M_{S}-1\right\rangle+\right. & \\
& \left.+b\left(M_{S}\right)\left|{ }^{4} \mathrm{~T}_{1-1}^{i}, M_{S}+1\right\rangle+c\left(M_{S}\right)\left|{ }^{4} \mathrm{~T}_{10}^{(i)}, M_{S}\right\rangle\right] .
\end{aligned}
$$

The values for $a\left(M_{S}\right), b\left(M_{S}\right), c\left(M_{S}\right)$ are given in [15]; $\zeta$ is the spin orbit coupling constant.

The dynamic part $V_{\mathrm{OL}}$ of the cristalline field is described with Van Vleck's normal mode model [16]. The $X Y_{4}$ system of the $\mathrm{Mn}^{2+}$ ion and its four sulfur nearest neighbours is shown in figure 11. This system possesses 9 normal coordinates, which are of symmetry $A_{1}, E, T_{2}$. The coordinate with $A_{1}$ symmetry does not contribute to our relaxation process, since it does not change $M_{S}$. We choose a linear combination of the displacements in such a way that only one of the two $\mathrm{T}_{2}$ representations contribute to relaxation. We then obtain :

$$
\begin{aligned}
Q_{\theta} & =\frac{1}{2 \sqrt{6}}\left[X_{1}+X_{2}-X_{3}-X_{4}+Y_{1}-Y_{2}-Y_{3}+Y_{4}-2\left(Z_{1}-Z_{2}+Z_{3}-Z_{4}\right)\right] \\
Q_{\varepsilon} & =\frac{1}{2 \sqrt{2}}\left[-X_{1}-X_{2}+X_{3}+X_{4}+Y_{1}-Y_{2}-Y_{3}+Y_{4}\right] \\
Q_{\mathrm{T}_{2 \xi}} & =\frac{1}{2 \sqrt{2}}\left[Y_{1}-Y_{2}+Y_{3}-Y_{4}+Z_{1}-Z_{2}-Z_{3}+Z_{4}\right] \\
Q_{\mathrm{T}_{2 \eta}} & =\frac{1}{2 \sqrt{2}}\left[X_{1}-X_{2}+X_{3}-X_{4}+Z_{1}+Z_{2}-Z_{3}-Z_{4}\right] \\
Q_{\mathrm{T}_{2 \xi}} & =\frac{1}{2 \sqrt{2}}\left[X_{1}-X_{2}-X_{3}+X_{4}+Y_{1}+Y_{2}-Y_{3}-Y_{4}\right]
\end{aligned}
$$

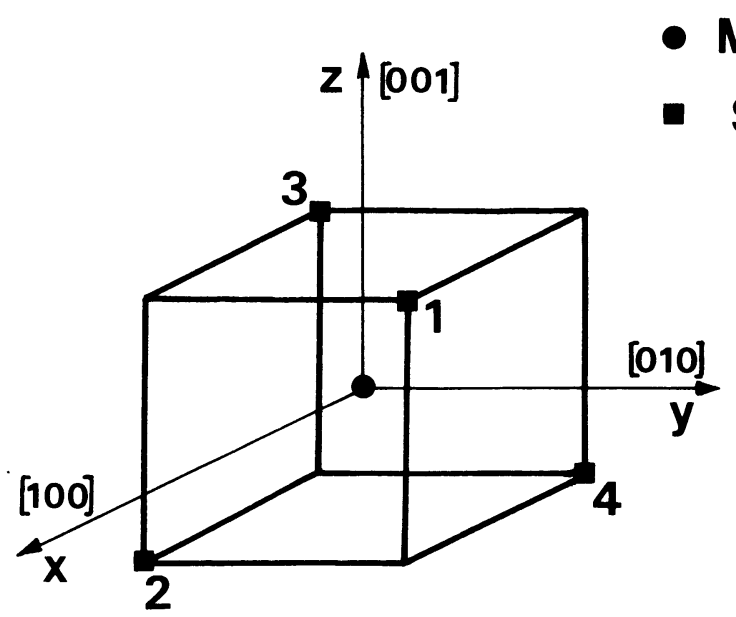

Fig. 11. - Positions of the nearest neighbours of $\mathrm{Mn}^{2+}$ with respect to the crystalline axes.

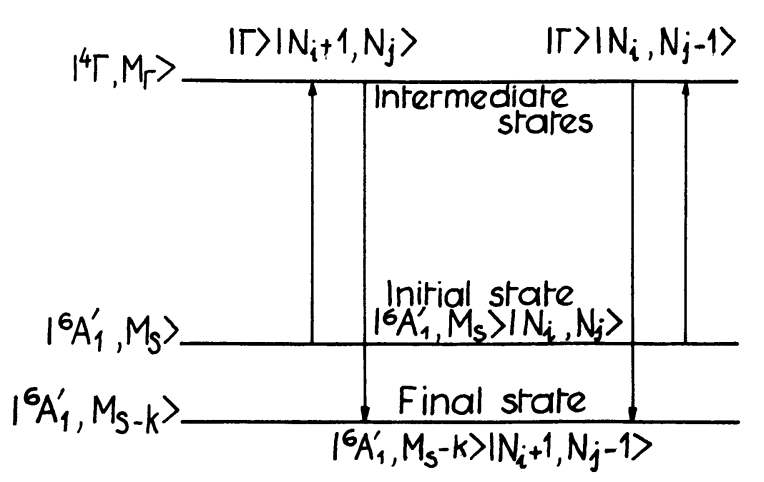

FIG. 12. - Diagram of the perturbation scheme for the Raman process. 
where $(X i, Y i, Z i)$ are the displacements of ion $i$ in figure 11. In the case of a homogeneous deformation (appendix 2), and using a complex basis for easier calculations, we obtain :

with

$$
V_{\mathrm{OL}}=\sum_{\Gamma, M_{\Gamma}} V\left(\Gamma, M_{\Gamma}\right) \cdot Q\left(\Gamma, M_{\Gamma}\right)^{*}
$$

$$
\begin{aligned}
Q_{\varepsilon}^{\mathrm{E}} & =R \sqrt{\frac{2}{3}}\left(\varepsilon_{22}-\varepsilon_{11}\right) \\
Q_{\theta}^{\mathrm{E}} & =\frac{R \sqrt{2}}{3}\left(\varepsilon_{11}+\varepsilon_{22}-2 \varepsilon_{33}\right) \\
Q_{\mathrm{T}_{21}} & =\frac{2 R}{\sqrt{3}}\left(\varepsilon_{13}-i \varepsilon_{23}\right) \\
Q_{\mathrm{T}_{20}} & =\frac{i 2 \sqrt{2}}{\sqrt{3}} R \varepsilon_{12} \\
Q_{\mathrm{T}_{2-1}} & =\frac{2 R}{\sqrt{3}}\left(\varepsilon_{13}+i \varepsilon_{23}\right) .
\end{aligned}
$$

The expressions of the $V\left(\Gamma, M_{\Gamma}\right)$ are given in appendix 3 . The normal coordinates are easily analysed in terms of phonon operators using (13), (14) and (27).

The perturbation scheme used is illustrated in figure 12, where :

$N_{i}$ is the number of phonons in the mode $(\mathbf{k}, s)$, with $\omega_{k, s}=v_{s} k$,

$N_{j}$ is the number of phonons in the mode $\left(\mathbf{k}^{\prime}, s^{\prime}\right)$, with $\omega_{k^{\prime} s^{\prime}}=v_{s^{\prime}} k^{\prime}$;

energy conservation requires that $K \omega_{0}=\omega_{k s}-\omega_{k^{\prime} s^{\prime}}$.

Since $V_{\mathrm{OL}}$ does not act on spin, then only ${ }^{4} \Gamma$ states must be considered.

We obtain from second order perturbation theory, and noting that $\omega_{k s}, \omega_{k^{\prime} s^{\prime}} \ll\left|E\left({ }^{6} \mathrm{~A}_{1}^{\prime}\right)-E\left({ }^{4} \Gamma_{i}\right)\right|$ :

$$
W_{M^{\prime} \rightarrow M_{s}-K}=\frac{2 \Pi}{\hbar^{2}} \sum_{\substack{s, s^{\prime} \\ \mathbf{k}, \mathbf{k}^{\prime}}}\left[\int\left|A_{i j}+B_{i j}\right|^{2}\left(\frac{V^{2}}{8 \Pi^{3}}\right)^{2} \frac{\omega_{k s}^{2} \omega_{k^{\prime} s^{\prime}}^{2}}{v_{s}^{3} v_{s^{\prime}}^{3}} \mathrm{~d} \Omega \mathrm{d} \Omega^{\prime} \mathrm{d} \omega_{k s}\right]_{\omega_{k^{\prime} s^{\prime}}=\omega_{k s}-K \omega_{0} \sim \omega_{k s}}
$$

with :

$$
\begin{aligned}
A_{i j} & =\sum_{{ }^{4} \Gamma_{i}, M_{\Gamma_{i}}} \frac{\left\langle{ }^{6} \mathrm{~A}_{1}^{\prime} M_{S}-K, N_{j}-1\left|V_{\mathrm{OL}}\right|{ }^{4} \Gamma_{i} M_{\Gamma_{i}}, N_{j}\right\rangle\left\langle{ }^{4} \Gamma_{i} M_{\Gamma_{i}}, N_{i}+1\left|V_{\mathrm{OL}}\right|{ }^{6} A_{1}^{\prime} M_{S}, N_{i}\right\rangle}{E\left({ }^{6} \mathrm{~A}_{1}^{\prime}\right)-E\left({ }^{4} \Gamma_{i}\right)} \\
B_{i j} & =\sum_{{ }^{4} \Gamma_{i}, M_{\Gamma_{i}}} \frac{\left\langle{ }^{6} \mathrm{~A}_{1}^{\prime} M_{S}-K, N_{i}+1\left|V_{\mathrm{OL}}\right|{ }^{4} \Gamma_{i} M_{\Gamma_{i}}, N_{i}\right\rangle\left\langle{ }^{4} \Gamma_{i} M_{\Gamma_{i}}, N_{j}-1\left|V_{\mathrm{OL}}\right|{ }^{6} A_{1}^{\prime} M_{S}, N_{j}\right\rangle}{E\left({ }^{6} \mathrm{~A}_{1}^{\prime}\right)-E\left({ }^{4} \Gamma_{i}\right)}
\end{aligned}
$$

$\mathrm{d} \Omega$ and $\mathrm{d} \Omega^{\prime}$ are related to the possible $\mathbf{k}$, and $\mathbf{k}^{\prime}$ directions respectively.

The following integrals occur frequently in the calculation,

where for any $Q_{\Gamma, M_{\Gamma}} \frac{\mathrm{d} \Omega}{4 \Pi}\left|\left\langle N_{i}+1\left|Q_{\Gamma, M_{\Gamma}}\right| N_{i}\right\rangle\right|^{2}=\left(N_{i}+1\right)\left(\frac{\hbar}{2 M \omega_{k s}}\right) k_{s}^{2} \bar{f}_{s, \Gamma, M_{\Gamma}}$

$$
\bar{f}_{L}=\frac{8}{45} R^{2} \quad \bar{f}_{T_{1}}+\bar{f}_{T_{2}}=\frac{3}{2} \bar{f}_{L} .
$$

Straightforward calculations lead to the following non zero probabilities :

where

$$
W_{5 / 2 \rightarrow 3 / 2}=\left[\zeta^{2} c\left(\frac{3}{2}\right) a\left(\frac{5}{2}\right)\right]^{2}\left[\left(C_{1}-\sqrt{3} C_{2}\right)^{2}+\left(C_{3}-C_{4}+C_{5}-\frac{1}{2} C_{6}\right)^{2}\right] \cdot A
$$

$$
A=\frac{1}{4 \Pi^{3} \rho^{2}}\left(\frac{1}{v_{L}^{5}}+\frac{3}{2} \frac{1}{v_{T}^{5}}\right)^{2}\left(\frac{8}{45} R^{2}\right)^{2}\left(\frac{k T}{\hbar}\right)^{7} I_{6}\left(\frac{\theta_{\mathrm{D}}}{T}\right)
$$

with

$$
I_{6}\left(x_{0}\right)=\int_{0}^{x_{0}} \frac{\mathrm{e}^{x} x^{6}}{\left(\mathrm{e}^{x}-1\right)^{2}} \mathrm{~d} x, \quad v_{T}=v_{T_{1}}=v_{T_{2}},
$$


$\theta_{\mathbf{D}}$ is the Debye temperature $\left(\theta_{\mathbf{D}} \ll\left|E\left({ }^{6} \mathbf{A}_{1}^{\prime}\right)-E\left({ }^{4} \Gamma_{i}\right)\right|\right)$ :

$$
\begin{aligned}
& W_{5 / 2 \rightarrow 1 / 2}= {\left[\zeta^{2} b\left(\frac{1}{2}\right) a\left(\frac{5}{2}\right)\right]^{2}\left\{\left(C_{1}-\sqrt{3} C_{2}\right)^{2}+\frac{-3}{4}\left(C_{7}-C_{8}\right)^{2}+\right.} \\
&\left.+2\left[\left(\frac{3}{4} C_{6}-C_{3}\right)^{2}+\left(\frac{1}{4} C_{6}-C_{5}-C_{4}\right)^{2}\right]\right\} \cdot A \quad(32 c) \\
& W_{3 / 2 \rightarrow 1 / 2}=\frac{2}{5} W_{5 / 2 \rightarrow 3 / 2} \quad W_{3 / 2 \rightarrow-1 / 2}=\frac{9}{5} W_{5 / 2 \rightarrow 1 / 2} \quad W_{M_{S} \rightarrow M_{S}-K}=W_{-M_{S}+K \rightarrow-M_{S}} \quad W_{1 / 2 \rightarrow-1 / 2}=0
\end{aligned}
$$

(Van Vleck's cancellation; the $T^{9}$ dependence is neglected).

The quantities $C_{1}$ to $C_{8}$ are related to the matrix elements of the $V\left(\Gamma, M_{\Gamma}\right)$. Their expression is given in appendix 4.

Using (6) and (32c) we obtain in the spin-temperature range :

$$
\frac{1}{T_{1}}=\frac{4}{25}\left[W_{5 / 2 \rightarrow 3 / 2}+8 W_{5 / 2 \rightarrow 1 / 2}\right]
$$

This expression is, strictly speaking, only valid when $T_{1}<T_{\mathrm{D}}$. However, when $T$ increases and $T_{1}$ becomes greater than $T_{\mathrm{D}}$, the gradual variation of the coefficients in the linear combination given by (33), is hidden by the far more important variation of the transition probabilities with temperature.

In our case

$$
\begin{gathered}
\zeta=300 \mathrm{~cm}^{-1}, \quad c\left(\frac{3}{2}\right) a\left(\frac{5}{2}\right)=\sqrt{10}, \\
b\left(\frac{1}{2}\right) \quad a\left(\frac{5}{2}\right)=\frac{\sqrt{10}}{2}, \quad R=2.34 \AA \\
10 D_{q}=4200 \mathrm{~cm}^{-1}[17]
\end{gathered}
$$

we take

$$
\frac{\left\langle r^{4}\right\rangle}{\left\langle r^{2}\right\rangle}=5 a_{0}^{2} \quad \text { with } \quad a_{0}=0.528 \AA[18] .
$$

After a numerical calculation of the $C_{i}$ we obtain with the previous values for $\rho, v_{L}, v_{T}$ :

$$
\begin{aligned}
& W_{5 / 2 \rightarrow 3 / 2}=5.6 \times 10^{-11} T^{7} I_{6}\left(\frac{\theta_{\mathrm{D}}}{T}\right)= \\
& =2.1 W_{5 / 2 \rightarrow 1 / 2}, \\
& \frac{1}{T_{1}}=4.3 \times 10^{-11} T^{7} I_{6}\left(\frac{\theta_{\mathrm{D}}}{T}\right) \quad\left(T_{1} \mathrm{~s}, T \mathrm{~K}\right) .
\end{aligned}
$$

Remembering the complexity of the problem, which compels us to several approximations (pointcharge model, linear dispersion law, use of two mean velocities $v_{L}$ and $v_{T}$ ) we may conclude that the theoretical and experimental results are in fairly good agreement. Our treatment also shows that the relaxation process is mainly due to transverse phonons $\left(v_{T}^{-5} \gg v_{L}^{-5}\right)$. K. Kunc in his thesis [19] shows that the density of states of cubic $\mathrm{ZnS}$ for acoustic transverse phonon modes falls off in the vicinity of $T=170 \mathrm{~K}$. This temperature compares favourably with the value of $168 \mathrm{~K}$ which occurs in the $I_{6}$ integral.

We must finally note that Orbach and Blume [21] have shown that for an ion with a quenched orbital moment, a Raman process can take place between states of the ground level. In that case the relaxation rate follows a $T^{5}$ temperature dependence. This process is more effective than the $T^{7}$ Raman one when the temperature is such that $k T<\zeta^{2} / \Delta(\Delta$ is the energy of the first excited state). In our case $\left(\zeta=300 \mathrm{~cm}^{-1}, \Delta=18000 \mathrm{~cm}^{-1}\right)$, this condition is satisfied when $T<7 \mathrm{~K}$. We have not observed such a law experimentally in this temperature range because the main contribution comes from the direct process.

6. Conclusion. - Our experiments show that at low temperatures $(T<20 \mathrm{~K})$, the whole system acquires a spin-temperature through a temperature independent diffusion process. When $T<10 \mathrm{~K}$, the relaxation takes place via a direct process. When $T>10 \mathrm{~K}$, we have a Raman process

$$
\left(\frac{1}{T_{1}} \propto T^{7} I_{6}\left(\frac{168}{T}\right)\right),
$$

with slight orientation dependence. Use of the static spin-lattice coefficients instead of the dynamic ones for the direct process is satisfactory. The calculation of the Raman process from first principles gives a value which is an order of magnitude greater than the experimental one. In both case transverse phonons are the most efficient.

Acknowledgments. - We would like to thank Pr. J. Hervé for his deep interest in this work.

We are indebted to G. Mailhan and A. Ouaknine for their technical assistance. 
Appendix 1. - $[20]$.

\begin{tabular}{|c|c|c|c|c|c|c|c|}
\hline$\alpha_{i}$ & $\beta_{i}$ & $\gamma_{i}$ & $\Delta_{i}=E\left({ }^{4} \mathrm{~T}_{1}^{i}\right)-E\left({ }^{6} \mathrm{~A}_{1}^{\prime}\right) \mathrm{cm}^{-1}$ & $\alpha_{i}^{\prime}$ & $\beta_{i}^{\prime}$ & $\gamma_{i}^{\prime}$ & $\Delta_{i}^{\prime}=E\left({ }^{4} \mathrm{~T}_{2}^{i}\right)-E\left({ }^{6} \mathrm{~A}_{1}^{\prime}\right) \mathrm{cm}^{-1}$ \\
\hline$\overline{0} 60$ & $\overline{009}$ & $\overline{0} 70$ & $18 \overline{400}$ & $\overline{0}$ & $\overline{-100}$ & $\overline{0} 07$ & $20 \overline{070}$ \\
\hline $\begin{array}{l}-0.60 \\
-0.05\end{array}$ & $\begin{array}{l}0.09 \\
0.99\end{array}$ & $\begin{array}{r}0.79 \\
-015\end{array}$ & $\begin{array}{l}18420 \\
35180\end{array}$ & $\begin{array}{r}-0.14 \\
0.28\end{array}$ & $\begin{array}{l}0.22 \\
0.94\end{array}$ & $\begin{array}{r}0.97 \\
-017\end{array}$ & $\begin{array}{l}20870 \\
36360\end{array}$ \\
\hline 0.80 & 0.13 & 0.59 & 26150 & 0.95 & -0.25 & $\begin{array}{r}-0.11 \\
0.19\end{array}$ & $\begin{array}{l}30300 \\
25040\end{array}$ \\
\hline
\end{tabular}

Appendix 2. - For a homogenous deformation :

$$
\begin{aligned}
& X_{i}=\varepsilon_{x x} x_{i}+\varepsilon_{x y} y_{i}+\varepsilon_{x z} z_{i}, \\
& Y_{i}=\varepsilon_{x y} x_{i}+\varepsilon_{y y} y_{i}+\varepsilon_{z y} z_{i}, \\
& Z_{i}=\varepsilon_{x z} x_{i}+\varepsilon_{y z} y_{i}+\varepsilon_{z z} z_{i},
\end{aligned}
$$

$\left(x_{i}, y_{i}, z_{i}\right)$ are the coordinates of atom $i$ at its equilibrium position;

$\left(X_{i}, Y_{i}, Z_{i}\right)$ are the coordinates of its displacement from this position.

Appendix 3. - Taking into account the first neighbours only, and using Van Vleck's point charge model, we get

$$
V\left(\Gamma, M_{\Gamma}\right)=\sum_{i} V_{i}\left(\Gamma, M_{\Gamma}\right)
$$

(the sum is over the electrons), where :

$$
\begin{gathered}
V_{i}(\mathrm{E}, \theta)=\alpha D_{0}^{(2)}+\beta\left[\frac{\sqrt{7}}{\sqrt{10}}\left(D_{-4}^{(4)}+D_{4}^{(4)}\right)-D_{0}^{(4)}\right] \\
V_{i}(\mathrm{E}, \varepsilon)=\frac{\alpha}{\sqrt{2}}\left[D_{-2}^{(2)}+D_{2}^{(2)}\right]+\frac{\sqrt{6}}{\sqrt{5}} \beta\left[D_{-2}^{(4)}+D_{2}^{(4)}\right] \\
V_{i}\left(T_{21}\right)=\sqrt{2} \delta D_{-1}^{(2)}+\sqrt{2} \delta^{\prime}\left[D_{-1}^{(4)}-\sqrt{7} D_{3}^{(4)}\right] \\
V_{i}\left(\mathrm{~T}_{20}\right)=\delta\left[D_{2}^{(2)}-D_{-2}^{(2)}\right]+2 \sqrt{2} \delta^{\prime}\left[D_{-2}^{(4)}-D_{2}^{(4)}\right] \\
V_{i}\left(\mathrm{~T}_{2-1}\right)=-\sqrt{2} \delta D_{1}^{(2)}+\sqrt{2} \delta^{\prime}\left[\sqrt{7} D_{-3}^{(4)}-D_{1}^{(4)}\right] \\
\alpha=-\frac{2 \sqrt{2}\left|e e_{\text {eff }}\right|}{R^{4}}, \quad \beta=-\frac{10 \sqrt{2} \frac{\left|e e_{\text {eff }}\right|}{R^{6}}}{9=-\frac{4}{3} \frac{\left|e e_{\text {eff }}\right|}{R^{4}},} \quad \delta^{\prime}=\frac{5 \sqrt{5} \frac{\left|e e_{\text {eff }}\right|}{3 \sqrt{6}}}{R^{6}} \\
10 D_{q}=-\frac{20}{27} \frac{\left|e e_{\text {eff }}\right|}{R^{5}}\left\langle r^{4}\right\rangle, \quad D_{q}^{(k)}=\sqrt{4 \Pi / 2 k+1} r_{i}^{k} Y_{k}^{q}\left(\theta_{i}, \varphi_{i}\right) .
\end{gathered}
$$

Appendix 4. - In the calculation (Raman process) use is made of the reduced matrix elements

$$
\left\langle{ }^{4} \Gamma_{i}\left|V_{\Gamma}\right|{ }^{4} \Gamma_{j}\right\rangle,
$$

which are related through the Clebsch-Gordan coefficients (ref. [14], A 20) to the following quantities :

$$
\begin{aligned}
& M_{1 i j}=\left\langle\mathrm{T}_{10}^{(i)}|V(\mathrm{E}, \theta)| \mathrm{T}_{10}^{(j)}\right\rangle=\frac{-2 \beta\left\langle r^{4}\right\rangle}{3 \sqrt{5}}\left[2\left(\alpha_{i} \gamma_{j}+\gamma_{i} \alpha_{j}\right)-\left(\beta_{i} \gamma_{j}+\gamma_{i} \beta_{j}\right)\right] \\
& M_{2 i j}=\left\langle\mathrm{T}_{10}^{(i)}|V(\mathrm{E}, \varepsilon)| \mathrm{T}_{20}^{(j)}\right\rangle=-\frac{2 \alpha\left\langle r^{2}\right\rangle}{7 \sqrt{35}}\left[7 \alpha_{i} \alpha_{j}^{\prime}+4 \beta_{i} \alpha_{j}^{\prime}+5 \sqrt{3} \beta_{i} \gamma_{j}^{\prime}+\sqrt{35} \gamma_{i} \beta_{j}^{\prime}\right]- \\
& -\frac{2 \beta\left\langle r^{4}\right\rangle}{7 \sqrt{105}}\left[14 \alpha_{i} \gamma_{j}^{\prime}+10 \sqrt{3} \beta_{i} \alpha_{j}^{\prime}+13 \beta_{i} \gamma_{j}^{\prime}-\sqrt{105} \gamma_{i} \beta_{j}^{\prime}\right] \\
& M_{3 i j}=\left\langle{ }^{4} A_{2}\left|V\left(\mathrm{~T}_{20}\right)\right| \mathrm{T}_{10}^{(i)}\right\rangle=\frac{2 \sqrt{2}}{7} \delta \gamma_{i}\left\langle r^{2}\right\rangle+\frac{4}{7} \sqrt{\frac{5}{3}} \delta^{\prime} \gamma_{i}\left\langle r^{4}\right\rangle
\end{aligned}
$$




$$
\begin{aligned}
& M_{4 i}=\left\langle\mathrm{E}_{\varepsilon}(\mathrm{D})\left|V\left(\mathrm{~T}_{20}\right)\right| \mathrm{T}_{10}^{(i)}\right\rangle=-\frac{2 \sqrt{2} \delta\left\langle r^{2}\right\rangle}{\sqrt{35}}\left(\alpha_{i}+\frac{4}{7} \beta_{i}\right)+\frac{40}{7 \sqrt{21}} \beta_{i} \delta^{\prime}\left\langle r^{4}\right\rangle \\
& M_{5 i}=\left\langle\mathrm{E}_{\varepsilon}(\mathrm{G})\left|V\left(\mathrm{~T}_{20}\right)\right| \mathrm{T}_{10}^{(i)}\right\rangle=-\frac{2}{7} \sqrt{\frac{30}{7} \delta\left\langle r^{2}\right\rangle \beta_{i}+\frac{4 \delta^{\prime}\left\langle r^{4}\right\rangle}{3 \sqrt{7}}\left(2 \alpha_{i}+\frac{13}{7} \beta_{i}\right)} \\
& M_{6 i j}=\left\langle\mathrm{T}_{1-1}^{(i)}\left|V\left(\mathrm{~T}_{20}\right)\right| \mathrm{T}_{11}^{(j)}\right\rangle=\frac{\sqrt{15} \delta\left\langle r^{2}\right\rangle}{7 \sqrt{2}}\left(\beta_{i} \gamma_{j}+\gamma_{i} \beta_{j}\right)+\frac{2 \delta^{\prime}\left\langle r^{4}\right\rangle}{3}\left[\left(\alpha_{i} \gamma_{j}+\gamma_{i} \alpha_{j}\right)+\frac{4}{7}\left(\beta_{i} \gamma_{j}+\gamma_{i} \beta_{j}\right)\right] \\
& M_{7 i j}=\left\langle\mathrm{T}_{2,1}^{(i)}\left|V\left(\mathrm{~T}_{20}\right)\right| \mathrm{T}_{1,1}^{(j)}\right\rangle=\delta\left\langle r^{2}\right\rangle\left[\sqrt{\frac{2}{35}} \alpha_{i}^{\prime}\left(-\alpha_{j}+\frac{16}{7} \beta_{j}\right)-\frac{3}{7 \sqrt{2}} \beta_{i}^{\prime} \gamma_{j}+\frac{\sqrt{15}}{7 \sqrt{14}} \gamma_{i}^{\prime} \beta_{j}\right]+ \\
&+\delta^{\prime}\left\langle r^{4}\right\rangle\left[-\frac{10}{7 \sqrt{21}} \alpha_{i}^{\prime} \beta_{j}+\frac{4 \sqrt{5}}{7 \sqrt{3}} \beta_{i}^{\prime} \gamma_{j}-\frac{10}{3 \sqrt{7}} \gamma_{i}^{\prime}\left(\alpha_{j}+\frac{2}{7} \beta_{j}\right)\right] .
\end{aligned}
$$

In the following definition of the $C_{i}$, there occurs the quantity $a_{i k}=\alpha_{i} \alpha_{k} / \Delta_{i} \Delta_{k}$ :

$$
\begin{aligned}
C_{1} & =\sum_{i j k} \frac{M_{6 i j} M_{1 j k}}{\Delta_{j}} a_{i k} & C_{2} & =\sum_{i j k} \frac{M_{7 j i} M_{2 k j}}{\Delta_{j}^{\prime}} a_{i k} \\
C_{3} & =\sum_{i j k} \frac{M_{6 i j} M_{6 j k}}{\Delta_{j}} a_{i k} & C_{4} & =\sum_{i j k} \frac{M_{7 i j} M_{7 j k}}{\Delta_{j}^{\prime}} a_{i k} \\
C_{5} & =\frac{1}{\Delta_{\mathrm{F}}} \sum_{i, k} M_{3 i} M_{3 k} a_{i k} & C_{6} & =\sum_{i, k}\left[\frac{M_{4 i} M_{4 k}}{\Delta_{\mathrm{D}}}+\frac{M_{5 i} M_{5 k}}{\Delta_{\mathrm{G}}}\right] a_{i k} \\
C_{7} & =\sum_{i j k} \frac{M_{1 i j} M_{1 j k}}{\Delta_{j}} a_{i k} & C_{8} & =\sum_{i j k} \frac{M_{2 i j} M_{2 k j}}{\Delta_{j}^{\prime}} a_{i k} .
\end{aligned}
$$

\section{References}

[1] Leushin, A. M., Sov. Phys. Solid State 5 (1963) 440.

[2] Blume, M., Orbach, R., Phys. Rev. 127 (1962) 1587.

[3] Wagner, G. R., CASTle, J. G., MurPhy, J., II-VI Semiconducting compounds, 1967 International Conference (D. G. Thomas ed.) W. A. Benjamin inc. 1212.

[4] Buch, T., Clerjaud, B., Lambert, B., Kovacs, P., Phys. Rev. B 7 (1973) 184.

[5] Matarese, L. M., Kikuchi, C., J. Phys. \& Chem. Solids 1 (1956) 117

[6] SCHNEIDER, J., SiRCAR, S. R., RÄUBeR, A., Z. Naturforsch. 18a (1963) 980.

[7] Blanc, C., Deville, A., Herve, J., Roger, G., J. Phys. E 5 (1972) 343.

[8] Le NAOUR, R., Thèse d'Etat Rennes (1968).

[9] Parrot, R., Blanchard, C., Boulanger, D., Phys. Lett. 34A (1971) 109.
'[10] Stevens, K. W. H., Rep. Prog. Phys. 30 (1967) 189.

[11] NyE, J. F., Physical properties of crystals (the Clarendon Press Oxford) 1957.

[12] Kondo, J., Prog. Theor. Phys. Suppl. 28 (1962) 1026.

[13] SLATER, J. C., Quantum theory of atomic structure Vol. II. (Mc. Graw-Hill) 1960.

[14] GRIFFITH, J. S., The theory of transition-metal ions (Cambridge University Press) 1964.

[15] Sharma, R. R., Das, T. P., Orbach, R., Phys. Rev. 149 (1966) 257.

[16] Van Vleck, J. H., Phys. Rev. 57 (1940) 426.

[17] Blanchard, C., Thèse d'Etat Aix-Marseille I (1974).

[18] Blume, M., Orbach, R., Phys. Rev. 127 (1962) 1587.

[19] Kunc, K., Thèse d'Etat. Paris VI (1973).

[20] LANDI, A., Thèse $3^{\mathrm{e}}$ cycle Aix-Marseille I (1971).

[21] Orbach, R., Blume, M., Phys. Rev. Lett. 8 (1962) 478. 